\title{
The Present-Day Tendencies of Teaching Informatics in Ukraine
}

\author{
Oleg Spirin \\ Department of Information Technology, Zhytomyr Ivan Franko University, \\ 40 vul. V.Berdychivska, 10008 Zhytomyr, Ukraine \\ somezu.edu.ua
}

\begin{abstract}
The article describes the present-day situation and general approach to teaching informatics in secondary schools in Ukraine. The syllabus of teaching informatics in Ukrainian schools is described, including major topics and the number of academic hours.
\end{abstract}

\section{Major Features of the Course in Informatics at Secondary Schools}

The main objective of informatics teaching is to provide students with theoretical knowledge in the basics of informatics and the development of practical skills in using present-day information technology in students' every-day practical learning.

The theoretical basis comprises the following components: the concept of information, its properties, informational processes and systems; general principles of computer-aided problem solution based on common and application programs; problem definition; construction of corresponding informational (mathematical in particular) models; fundamentals of algorithmization and programming; principles of computer hardware; and opportunities for using the Internet).

Practical skills comprise work with information input and output devices, application software of both general and specific types: text processors, graphics editors, electronic worksheets, database management systems, search systems, teaching software tools, browsers for viewing hypertext pages, e-mail and teleconference software, searching for information on the Internet etc; also skills of development, description and implementation of some algorithms and programs based on algorithmical language tools and real programming languages.

Depending on the type of computers, teachware and software available, teachers can themselves choose the appropriate methods and techniques to achieve the aims of the course. According to the methods and techniques that are chosen, teachers select corresponding textbooks, manuals and teaching materials out of the list of resources recommended by the Ministry of Education and Science of Ukraine, combining various resources or giving emphasis to some of them.

Here is the list of the main topics and their sequence for the senior forms of general secondary schools in Ukraine [1]:

1. Information and informational processes.

2. Information system.

R.T. Mittermeir (Ed.): ISSEP 2005, LNCS 3422, pp. 75-83, 2005.

(c) Springer-Verlag Berlin Heidelberg 2005 
3. Operational system.

4. Fundamentals of disc handling.

5. Application teaching software.

6. General-purpose application software:

- graphic engine;

- text processor;

- computer presentations;

- electronic worksheet;

- databases.

7. The Internet.

8. Basics of algorithmization and programming:

- information model;

- algorithms;

- program. Programming language;

- reference to algorithms and functions;

- reference to repetitions and branching;

- table values;

- literal values;

- graphic operations.

In 2003 the Ministry of Education and Science determined the procedure of final public testing in informatics [2]. Two options are available: an oral examination or defence of students' papers describing the development of application software. The students themselves choose either of these two options. The second option can be chosen only by the best students who have the highest academic performance in informatics.

Teachers of informatics offer their students a list of recommended subjects for their research papers, taking into consideration inter-disciplinary connections and needs of teaching informatics. Students are free to take any topic which is of interest for them, has practical significance and relevance. A student's paper can be of educational, demonstrational, testing or gaming nature or can combine several features. The curriculum does not allocate any specific time for development of software by students - they do it as part of their homework and out-of-class activities.

A specific activity in informatics is the annual competitions held at several levels: I - school level, II - district or city level, III - regional level, IV - national level.

\section{Peculiarities of Teaching Informatics at School}

\subsection{Existing Syllabi}

Teaching informatics to senior students of Ukrainian secondary schools follows a syllabus with three variations, depending on the facilities available at schools. The first variant is for teaching informatics without actual use of computers, the second variant is for DOS-based teaching of informatics and the third variant is for WINDOWS-based teaching informatics. This three-variant syllabus has been in use 
since the late 1990s. This syllabus can be regarded as a transition period syllabus. One can expect that it will remain in effect for a rather long period of time, for more than five years to come.

This is connected with insufficient and unbalanced investments in the computer facilities of secondary schools. There is still a considerable number of schools which have out-of-date computers or no computers at all. In the latter case, informatics is taught basically in terms of fundamentals of algorithmization. Computer hard- and software are studied only theoretically. Practical skills are limited to skills in mathematical simulation, development of algorithms for problem solution, their graphic description in the form of flow charts. Algorithms can be described in terms of the Teaching Algorithmic Language (TAL), specifically developed in the early 1980s. The main references in this language are similar to PASCAL operators. TAL is intended for use in paper study of algorithmization, though a translator of this language exists which is used on old teaching hardware (mid-1980s - early 1990s).

The three-variant syllabus provides that if a school has sufficient computer facilities, the course of informatics covers two years, the total amount of academic hours being 102 hours (table 1.). Informatics lessons are often distributed as follows. In the first half-year students may have one lesson a week, and in the second half-year they have two lessons a week. Then in the second year they may have two lessons a week in the first half and one lesson in the second half of the year. Depending on the school curriculum, informatics can be studied in 8-9 or 10-11 forms.

Table 1. Here are the main components of the course of informatics

\begin{tabular}{|l|l|}
\hline Topic & Amount of hours \\
\hline Introduction. Information and informational processes & 3 hours \\
\hline Information system & 5 hours \\
\hline Operating systems & 9 hours \\
\hline Basic skills of disk handling & 5 hours \\
\hline Application software & 46 hours \\
\hline INTERNET and its basic possibilities & 6 hours \\
\hline Fundamentals of algorithmization and programming & 28 hours \\
\hline
\end{tabular}

\subsection{Further Changes in the Existing Syllabi}

Since 2003 Ukrainian schools have started the transition to profile (specialized) teaching in senior forms. Its aim is to provide the students with basic knowledge and skills for the job market. This education profile makes use of new syllabi in informatics developed specifically for the changed purposes of student's training. The minimal compulsory amount of hours for informatics during two years of study is 70 hours. The syllabi under consideration present an updated version of the WINDOWSbased syllabus within the earlier three-variant syllabus.

The first line is aimed at solving information problems involving information search, use and processing. From the practical point of view it aims at training a PC user at a corresponding level. These syllabi are used in universal-profile forms and those specializing in Philology, the Humanities, Fine Arts and sports. In these types of 
forms informatics is studied during two years, with one class per week (the total of 70 hours). The syllabi of this line have insignificant differences in their contents and amount of hours.

Table 2 shows the components of the course in informatics for the universal-profile schools.

Table 2. Distribution of topics for universal-profile schools

\begin{tabular}{|l|l|l|l|l|}
\hline$\#$ & Topic & \multicolumn{3}{l|}{ Hours } \\
\cline { 3 - 5 } & & Total & $\begin{array}{l}10 \\
\text { form }\end{array}$ & $\begin{array}{l}11 \\
\text { form }\end{array}$ \\
\hline 1. & $\begin{array}{l}\text { Introduction. Information and informational } \\
\text { processes. }\end{array}$ & 2 & 2 & \\
\hline 2. & Information systems and their components. & 6 & 6 & \\
\hline 3. & Application teaching software & 4 & 4 & \\
\hline 4. & $\begin{array}{l}\text { General-purpose application software (graphic } \\
\text { and text processors, computer presentations, } \\
\text { electronic worksheet, databases) }\end{array}$ & 34 & 14 & 20 \\
\hline 5. & Internet & 6 & 6 & 12 \\
\hline 6. & $\begin{array}{l}\text { Computer simulation. Basics of algorithmiza- } \\
\text { tion and programming. }\end{array}$ & 12 & & 35 \\
\hline & Float time & 6 & 3 & 3 \\
\hline & Total & 70 & 35 & 35 \\
\hline
\end{tabular}

Among the application software used in Ukraine is specialized computer teachware, certified by the Ministry of Education and Science, for example, "Videointerpreter of search and sorting algorithms", „Geography of continents and oceans with maps”, „Ancient Rome”, „Electronic course in modern history”, „Dynamic geometry package DG”, program packages GRAN-1, GRAN-2D, GRAN3D, GRANWIN, „Geography. Location map”, „Native language”, „Your health is in your hands”, „Ukraine and its regions”, ,Physics for a future engineer. Learning to solve problems”, „Regional transport systems”, interactive testing systems, etc.

The second line is aimed at the practical mastery of skills essential for work with the basic components of up-to-date computer software, familiarization with functions of major computer devices and the basic technologies of computer-aided problem solving, starting from the formulation and construction of information models up to the interpretation of results. These syllabi are designed for schools (or forms) specializing in physics, mathematics, biology, chemistry and technology. In such schools (or forms) informatics is studied during two years, with two classes per week (total 140 hours). The aim of the course is somewhat broader than the syllabus of the first line. It involves understanding the theoretical basis for processes of transformation, transmission and application of information, understanding the meaning and role of information processes in contemporary society, and the development of practical skills in the conscious and rational use of computers.

More hours (46-48) are allotted to the fundamentals of algorithmization and programming. Teaching programming involves the use of the translator of one of the programming languages (BASIC, PASCAL, C++, Visual Basic, Delphi, etc.). 
It should be mentioned at this point that the syllabi of the first and second lines are not satisfactory in the opinion of certain specialists in the methodologies of informatics.

These specialists point out considerable discrepancy between the existing concept of informatics teaching, international teaching standards, effective syllabi, the concept of profile teaching and the real situation in Ukrainian schools. One of the reasons for such discrepancy is absence of options at the level of teachware. At the same time there are active disputes as regards the "Algorithmization and programming" section, its place in the syllabus, components and order of studying topics. Most university specialists insist that this topic should take the central place in the school course in informatics. It should involve visual programming as its essential component.

The third line of syllabi provides for the study of informatics from the 7th or 8th form. Such syllabi were developed for forms specializing in deep study of mathematics, informatics and ICT. According to these syllabi, students have 2-4 hours of informatics in the 8th-9th forms (total 140-280 hours) and 4 hours per week in the 10th form (total 280 hours).

Most syllabi provide an integrated course - "Informatics and information technology". 7-9-formers can have a basic course at the expense of the optional (selective) hours provided in the curriculum. At the same time they can have the course in technology at the expense of hours allotted to labour training.

The course in technology for 7th-9th-formers involves teaching skills of vector and bitmapped graphics for polygraphy, multi-media programming and web-design.

In the 10th and 11th forms this integrated course is studied along one of the profiles: computer-aided design technologies, object-oriented programming languages, use of electronic worksheets in economics and business, web-design, architecture and landscape design.

Besides the above-mentioned compulsory syllabi students may have access to optional (selective) courses, such as:

- fundamentals of information technology (140 hours);

- Internet-oriented graphics programming (70 hours);

- markup language (40 hours);

- object-oriented visual programming (140 hours); etc.

\subsection{Who Defines How Informatics Should be Taught?}

All of the syllabi described above are approved by the Ministry of Education and Science of Ukraine. Depending on the available computer facilities and school profile, school administrations choose a certain syllabus. The syllabus chosen is approved by the local educational authorities which fund schools.

Where students are aiming at higher education in universities majoring in computer sciences, school authorities can allot more hours for deeper teaching of informatics, negotiating the changes in the syllabus with the corresponding university.

It is up to a teacher to choose specific methods of teaching. The main thing is that the teacher should guarantee meeting the ultimate standards of knowledge and skills specified in the syllabus. Consequently, the syllabus defines only the type of obligatory software, and it is up to the teacher to select the particular version. Teachers also define the textbooks to be used in the course of study. 


\subsection{Training of Teachers of Informatics}

The public system of training of teachers of informatics (Fig. 1) consists of two routes:

- 5-year university training majoring in informatics, mathematics and basic informatics, teaching of informatics at secondary schools; or 1-2-year post-diploma (further) course in informatics for university graduates;

- one-month free courses in informatics at regional institutions for further pedagogical education for teachers of mathematics and physics and for computer engineers who started their work at schools.

Working teachers of informatics take refresher courses once every five years. These one-month courses are provided by regional institutions for further pedagogical education. If school administrations have the opportunity to adopt a broader course of informatics due to improved computer facilities, teachers of these schools can take a refresher course before the scheduled time.

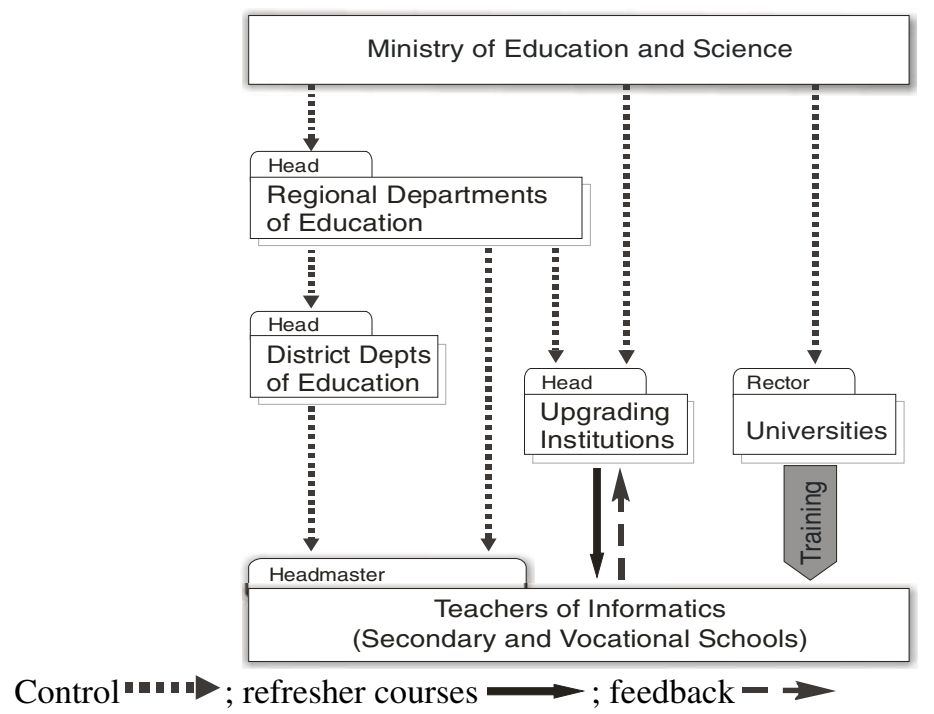

Fig. 1. Public system of training and retraining of teachers of informatics

Teachers of informatics are motivated to upgrade their professional competence by annual competitions for the best teachers of informatics. These competitions are organized by the regional institutions for further pedagogical education. Their winners take part in the national competition. The winners of these competitions are awarded diplomas and bonuses and put forward for higher professional categories, which means higher salaries.

Teachers of informatics can upgrade their competence on their own, making use of the national monthly journal "Computer at school and family" and the national newspaper for teachers which highlights issues relating to the informatization of 
secondary education, theoretical and practical issues of informatics teaching, methodological recommendations concerning teaching new software, feature discussion of the present-day situation in informatics teaching and its prospects, publishes samples of final tests and assignments for the national students' competition in informatics, review textbooks and manuals, etc.

Alongside traditional schemes of teachers' upgrading and retraining, an increasing role today is played by the initiatives of individual teachers. An example of one such initiative is the "Hot Summer" project, in which teachers of informatics submit electronically their best lesson plans for consideration by experts, share their successful methods and techniques. The organizers of this project collect the database and disseminate it among the participants for further discussion and use.

Teachers of informatics have also set up regional Internet Olimpiadas, involving the solution of advanced-level programming problems.

At the same time, the availability of qualified teachers of informatics remains a problem for Ukrainian schools. The main reason for this is the low salaries of school teachers in general. As a result, young promising teachers leave schools and seek better employment in other spheres. The beginning of 2003-2004 school year witnessed about 6,000 teachers' vacancies in 21,000 schools, mainly of teachers of informatics and foreign languages.

\subsection{Teachware}

One of the major problems today is the provision of adequate teachware (textbooks, manuals, software and test programs, teaching materials) for teaching informatics. Most of the existing textbooks which were financed by the Ministry rapidly become out-of-date and can not follow the changing syllabi. The quality of the textbooks and manuals is affected by the existing imperfect expertise procedure provided by the Ministry. Often such expertise is carried out formally. Some teachers of informatics try to fill this gap with their own teachware often developed in a hurry, lacking the necessary experience and competence for this. The resulting teachware is not always of appropriate quality.

This situation brought about some drastic demands for the Ministry to stop public financing of textbooks and manuals in informatics, in order to prevent large-scale invasion of low-quality teachware. Instead, it has been proposed that publishing houses should publish textbooks in informatics on the basis of commercial risk. In this way they would be able to react to rapid changes in informatics as a science and school discipline, and teachers would be able to choose a textbook out of several proposed titles.

\section{Some Prospects of School Informatics in Ukraine}

All of the description above shows that at present informatics in Ukrainian schools is studied following a number of syllabi oriented at various specialization profiles and levels. We expect that this trend will become even more prominent in the decade to come. At the same time the teachers' main efforts will be directed at searching for 
ways to eliminate discrepancies between the knowledge and skill standards declared in the syllabi and the actual knowledge and skills displayed by the students.

Some definite trends relating to teaching informatics in schools are listed below:

1. The structure of the school course in informatics is likely to change. In future it is likely to comprise three levels and follow the development of students' intellectual activity: 7th-8th forms - a basic course, 9th-10th forms - the main course, 11th form - the specialized course.

2. Alongside the expected change in the course structure, the future is likely to witness separation of the fundamental (mainly algorithmization and programming) and applied (IT) aspects of teaching informatics at schools. This trend may lead to differentiation of two subjects: the fundamentals course which will be taught by teachers of informatics and the applied aspects which may be taught not only by teachers of informatics, mathematics and physics but also by teachers of the humanities. Such a change will bring about the necessity of reforms both in the school teaching of informatics and in the system of university training of teachers, their further upgrading and retraining.

3. The introduction of informatics as a subject in primary school seems quite feasible. Some schools are carrying out the experimental teaching [3] of some introductory courses, like "Computer ABC" (for the first-formers), "Steps to informatics" (for the second-fourth-formers), "Introduction to informatics" (for the fifth-sixthformers). At the same time there is a strong belief that in primary school computers have to be used only as a means of teaching other subjects and that this should not be considered as teaching informatics proper.

4. Computers will be found not only in schools but also in students' homes. We expect that in future the students in the 5th-6th forms will show significant computer competence and in the 7th-8th forms they will have higher knowledge and better skills in using computers than ordinary teachers have today. This will have to bring about adequate changes in the syllabi and teachware, and the presentday concept of training PC users will have to be critically reassessed with the shift to algorithmization and solving typical problems.

5. A broader range of optional (selective) courses is expected. The training of PC users is expected to incorporate the comprehensive study of artificial intelligence software and general expert systems. In teaching programming there is a tendency of wider additional use of Internet-programming systems (ASP, PHP, Perl, Java, etc.) and systems of Internet publications (HTML, XML, XHTML). Some specialists [4] consider the possibility of incorporating LINUX systems into school courses in informatics. Yet we do not consider the prospect of using such operating systems and corresponding application software realistic.

6. An increase in investments in school computer facilities is quite feasible. Intensive improvement of school computer facilities is backed by the government program aimed at provision of every rural school with modern computers. Since 20012257 computer classrooms have been supplied to rural schools (about 1500 in 2004).

7. We can also expect a considerable inflow of well-trained teachers of informatics to schools in the immediate future. This trend is reinforced by the government's plans to conclude social agreements with university graduates, according to which those graduates whose tuition was covered from public funds will have to work at schools a specified number of years. 
8. One can expect formation of a professional association of teachers of informatics.

9. One can also expect that formerly isolated system of informatics teaching in Ukraine will enter the wider international environment (EU in particular). This tendency can find its realization in experience sharing, participation in international educational projects in the field of informatics and conferences.

\section{References}

1. Informatics. Syllabi for general secondary educational institutions. - Zaporizhzhya: Premier, 2003. - 304 pp. (in Ukrainian)

2. Methodological recommendations for the final public testing in informatics in 2002/2003 (in Ukrainian) http://www.mon.gov.ua/laws/list_1_9_39_.doc

3. V.M.Shevchenko. The structure of the course in informatics at school \# 52 // Computers at schools and in the family. - 2003. - \# 2 - P.27-28 (in Ukrainian)

4. Ya.M.Glynskyy, V.A.Ryazhska. Linux-practicum in informatics. Manual. - Lviv, Deol, 2004. - 248 pp. (in Ukrainian) 